\title{
Effects of reaction parameters on the electrochemical formation of multilayer films composed of manganese oxides and tetra-alkylammonium ions
}

\author{
Masaharu Nakayama, ${ }^{a}$ Masaki Fukuda, Sayaka Konishi, and Tsuyoshi Tonosaki \\ Faculty of Engineering, Department of Applied Chemistry, Yamaguchi University, 2-16-1 Tokiwadai, \\ Ube 755-8611, Japan
}

(Received 14 April 2006; accepted 24 August 2006)

\begin{abstract}
Multilayered manganese oxide films were prepared on a platinum electrode by potentiostatic oxidation of aqueous $\mathrm{Mn}^{2+}$ ions in the presence of $n$-tetra-alkylammonium compounds. Alkylammonium cations were intercalated between manganese oxide layers to balance the negative layer charge. Effects of several preparative parameters such as the size of alkylammonium molecules, counteranions, and bath composition on the structure of products were investigated. The interlayer distance of the products increased with increasing alkyl chain length up to $\mathrm{C} 4$, and the change became obviously small among $\mathrm{C} 4-\mathrm{C} 6$ compounds. The multilayer formation was achieved only when the manganese concentration was lower than $10 \mathrm{mM}$, and the highest crystallinity was obtained from a bath composed of $2 \mathrm{mM}$ manganese sulfate and $50 \mathrm{mM}$ alkylammonium chloride. At low concentrations of alkylammonium $(<10 \mathrm{mM})$, a product intercalated with hydrated protons was formed, in which the protons were generated by anodic oxidation of $\mathrm{Mn}^{2+}$ with $\mathrm{H}_{2} \mathrm{O}$.
\end{abstract}

\section{INTRODUCTION}

Nanostructured materials based on manganese dioxide have attracted considerable attention because of their unique adsorptive, ${ }^{1}$ catalytic, ${ }^{2}$ and electrochemical properties. ${ }^{3}$ Birnessite $\left(\delta-\mathrm{MnO}_{2}\right)$ has a two-dimensional layered structure consisting of edge-shared $\mathrm{MnO}_{6}$ octahedra. The manganese oxide layer is negatively charged because of the presence of $\mathrm{Mn}^{3+}$ ions substituted with $\mathrm{Mn}^{4+}$ in $\mathrm{MnO}_{2} \cdot{ }^{4}$ Small cations such as potassium ions or protons are normally situated in the interlayer space to balance the negative charges on manganese oxide layers. Some organoammonium ions can also be intercalated between the layers of chemically synthesized proton-type birnessite by ion-exchange, accompanying an expansion of the interlayer. ${ }^{5,6} \mathrm{~A}$ number of chemical procedures have so far been developed for the synthesis of birnessite, including oxidation of $\mathrm{Mn}^{2+}, 7$ reduction of $\mathrm{MnO}_{4}^{-8}$, and redox reactions between these two species. ${ }^{9}$ Formation of birnessite can be accomplished through the following steps: (i) formation of $\mathrm{Mn}(\mathrm{OH})_{2}$, (ii) oxidation of $\mathrm{Mn}(\mathrm{OH})_{2}$ to a $\mathrm{MnO}_{x}$ suspension, and (iii) aging of the $\mathrm{MnO}_{x}$ suspension to form birnessite. ${ }^{10} \mathrm{~A}$ synthesis experiment at room temperature required 75 days for complete crystallization of birnessite. ${ }^{10}$

\footnotetext{
a) Address all correspondence to this author.

e-mail: nkymm@yamaguchi-u.ac.jp

DOI: 10.1557/JMR.2006.0385
}

Among various strategies for fabrication of thin metal oxide films, electrochemical deposition is one of the most promising approaches, particularly for obtaining thin and uniform films on substrates of complex shape with a high degree of reproducibility. ${ }^{11,12}$ Electrodeposition is a low-cost method and is environmentally benign from the point of view that no heating is needed. More importantly, the structure of deposits can be finetuned with the variation of deposition baths, while the film thickness is controllable by simply changing the delivered electrical charge. However, no studies had been published on the electrochemical formation of layered manganese oxides until we reported it. ${ }^{13-17}$ Our process consists of a one-step potentiostatic oxidation of aqueous manganese(II) ions in the presence of alkaline metals, ${ }^{13}$ alkylammonium ions, ${ }^{15,16}$ or polycations, ${ }^{14,17}$ producing a thin film of manganese oxide adhering well to a substrate. Electrodeposition using $n$-tetraalkylammonium chlorides ranging in chain length from 1 to 4 carbons revealed that the interlayer distance of products increases almost linearly with an increase in the size of cations. Crystallinity of the films was varied depending on the electrode potential. X-ray diffraction patterns of the product increased in intensity with increasing electrolysis time, without changing the pattern, indicating successful construction of a multilayer. However, several experimental parameters have not yet been optimized.

In this article, we report the effects of preparative 
parameters such as the size of alkylammonium cations (with longer alkyl chain lengths), type of counteranions, and bath composition. X-ray diffraction and $\mathrm{x}$-ray photoelectron spectroscopy were used to characterize the products. Ion-exchange properties of the manganese oxide film intercalated with tetraethylammonium ions were also investigated.

\section{EXPERIMENTAL}

Tetrabutylammonium chloride $\left(\mathrm{Bu}_{4} \mathrm{~N}^{+} \mathrm{Cl}^{-}, 99 \%\right)$ was obtained from Fluka (Steinheim, Switzerland). Tetrapropylammonium chloride $\left(\mathrm{Pr}_{4} \mathrm{~N}^{+} \mathrm{Cl}^{-}, 98 \%\right)$, tetrapentylammonium chloride $\left(\mathrm{Pen}_{4} \mathrm{~N}^{+} \mathrm{Cl}^{-}, 98 \%\right)$, tetraethylammonium perchlorate $(95 \%)$, and tetraethylammonium tetrafluoroborate $(95 \%)$ were obtained from Wako Pure Chemicals (Osaka, Japan). Tetraethylammonium chloride $\left(\mathrm{Et}_{4} \mathrm{~N}^{+} \mathrm{Cl}^{-}, 99 \%\right)$ and tetraethylammonium $p$-toluensulfonate $(98 \%)$ were obtained from Tokyo Kasei (Tokyo, Japan). Tetramethylammonium chloride $\left(\mathrm{Me}_{4} \mathrm{~N}^{+} \mathrm{Cl}^{-}, 98 \%\right)$ and tetrahexylammonium chloride $\left(\mathrm{Hex}_{4} \mathrm{~N}^{+} \mathrm{Cl}^{-}, 98 \%\right)$ were obtained from Aldrich (St. Louis, MO). All other chemicals were of reagent grade and used as received. All solutions were prepared with doubly distilled water and deoxygenated by the bubbling of purified nitrogen gas for at least 20 min just prior to use.

Electrodeposition was conducted using a conventional three-electrode system in an undivided glass cell. A platinum sheet and a $\mathrm{Ag} / \mathrm{AgCl}$ electrode (in saturated $\mathrm{KCl}$ ) were used as the counter and reference electrodes, respectively. A Hokuto Denko HA-301 potentiostat (Tokyo, Japan) connected to a Hokuto Denko HB-104 function generator was used to control the electrode potential. Polycrystalline platinum foil $(99.98 \%)$ of a $1 \mathrm{~cm}^{2}$ surface area was used as the working electrode. The electrode surface was ultrasonically cleaned in diluted $\mathrm{HCl}$ solution for $10 \mathrm{~min}$ and then rinsed thoroughly with distilled water before each experiment. The deposition baths used were composed of $\mathrm{MnSO}_{4}$ and various $n$-tetraalkylammonium salts with different concentrations. A constant potential $(+1.0 \mathrm{~V})$ was applied to the working electrode for a certain period of time while the delivered charge was monitored. After electrodeposition, the resulting film coated on a Pt electrode was rinsed thoroughly with water, dried under vacuum in a desiccator for at least $2 \mathrm{~h}$, and then submitted to spectroscopic measurements within $6 \mathrm{~h}$. Ion-exchange experiments were carried out by immersing the as-deposited film on a Pt electrode into $0.1 \mathrm{M}$ solutions of $\mathrm{NH}_{4} \mathrm{Cl}$ or tetraalkylammonium chlorides with different alkyl chain lengths, mostly for $2 \mathrm{~h}$.

$\mathrm{X}$-ray diffraction (XRD) patterns were recorded using a Shimadzu XD-D1 diffractometer (Kyoto, Japan) with $\mathrm{Cu} \mathrm{K}$ radiation $(\lambda=0.15405 \mathrm{~nm})$. The data were collected in the $2 \theta$ range from $5^{\circ}$ to $60^{\circ}$ with a scan rate of $1^{\circ} \min ^{-1}$. The beam voltage was $30 \mathrm{kV}$, and the beam current was $30 \mathrm{~mA}$. X-ray photoelectron spectroscopy (XPS) was carried out using a Fisons Escalab 210 spectrometer (Beverly, MA), with an $\mathrm{Al} \mathrm{K} \mathrm{K}_{\alpha}(1486.6 \mathrm{eV})$ unmonochromatic source $(15 \mathrm{kV}, 20 \mathrm{~mA})$. Wide- and narrow-range spectra were collected with a pass energy of $20 \mathrm{eV}$ and channel widths of 0.1 and $0.01 \mathrm{eV}$, respectively. The binding energy (BE) scale was calibrated with respect to the $\mathrm{C} 1 s(284.5 \mathrm{eV})$ signal. Curve fitting was made by a mixture of Gaussian and Lorenzian functions, while background subtraction was done according to the Shirley method. Semiquantitative estimates of the relative atomic concentrations were obtained from the peak area ratios by taking into account the appropriate sensitivity factors: $\mathrm{Mn} 2 p_{3 / 2}=9.17, \mathrm{~N} 1 s=1.80$, and $\mathrm{Cl} 2 p_{3 / 2}=1.51$.

\section{RESULTS AND DISCUSSION}

\section{A. Synthesis with various alkylammonium chlorides}

Figure 1 displays XRD patterns of the films on a $\mathrm{Pt}$ electrode deposited from $2 \mathrm{mM} \mathrm{MnSO}_{4}$ solutions containing $50 \mathrm{mM}$ alkylammonium chlorides with varying alkyl chain lengths. In the case of $\mathrm{Et}_{4} \mathrm{~N}^{+}$, we can see a set of evenly spaced diffraction peaks, corresponding to $d$ spacings of $0.94,0.47$, and $0.32 \mathrm{~nm}$. These peaks are indexable to the $00 l$ reflections $(l=1,2$, and 3$)$ for a birnessite-type layered manganese oxide intercalated with $\mathrm{Et}_{4} \mathrm{~N}^{+}$cations, ${ }^{15}$ and the $d_{001}$ value $(0.94 \mathrm{~nm})$ corresponds to the interlayer distance. Other alkylammonium molecules also exhibit similar patterns indicative of the layered structure. The relationship between the observed $d_{001}$ values and the crystallographic radii ${ }^{18,19}$ of tetra-alkylammonium ions is shown in Table I and Fig. 2, in which the data for $\mathrm{Me}_{4} \mathrm{~N}^{+}(\mathrm{C} 1)$ and $\mathrm{Pr}_{4} \mathrm{~N}^{+}$(C3) in Ref. 15 are included. Using the ionic radius of $\mathrm{Et}_{4} \mathrm{~N}^{+}$ $(0.400 \mathrm{~nm})$, the dimensions of $\mathrm{Et}_{4} \mathrm{~N}^{+}$ion along its $C_{2}$ and $C_{3}$ rotation axes are calculated to be 0.462 and $0.533 \mathrm{~nm}$, respectively. A sum of the $\mathrm{Et}_{4} \mathrm{~N}^{+}$dimension in the $C_{3}$ axis $(0.533 \mathrm{~nm})$ and the thickness of one $\mathrm{MnO}_{2}$ sheet $(0.45 \mathrm{~nm})^{6}$ exceeds the observed interlayer distance of $0.94 \mathrm{~nm}$. Thus, the obtained repeating periodicity is attributable to accommodation of one molecular layer of $\mathrm{Et}_{4} \mathrm{~N}^{+}$ions with the $C_{2}$ rotation axis normal to the plane of manganese oxide. As previously indicated, $\mathrm{Me}_{4} \mathrm{~N}^{+}$ yielded a product consisting of two phases with $d_{001}=$ 0.98 and $0.75 \mathrm{~nm}$. Plots for the films prepared with $\mathrm{Et}_{4} \mathrm{~N}^{+}, \mathrm{Pr}_{4} \mathrm{~N}^{+}$, and $\mathrm{Bu}_{4} \mathrm{~N}^{+}$and the 0.75-nm plot for the $\mathrm{Me}_{4} \mathrm{~N}^{+}$sample can be fitted to a straight line, suggesting the intercalation of the corresponding alkylammonium ions in the same manner. The other plot (filled symbol) for the $\mathrm{Me}_{4} \mathrm{~N}^{+}$film deviates from the straight line. This can be ascribed to a higher degree of hydration of $\mathrm{Me}_{4} \mathrm{~N}^{+}$ ions, probably due to the lower hydrophobicity of $\mathrm{Me}_{4} \mathrm{~N}^{+}$ in comparison with other alkylammonium ions. Compared to the increase in $d$-spacing observed for $\mathrm{C} 1-\mathrm{C} 4$ 


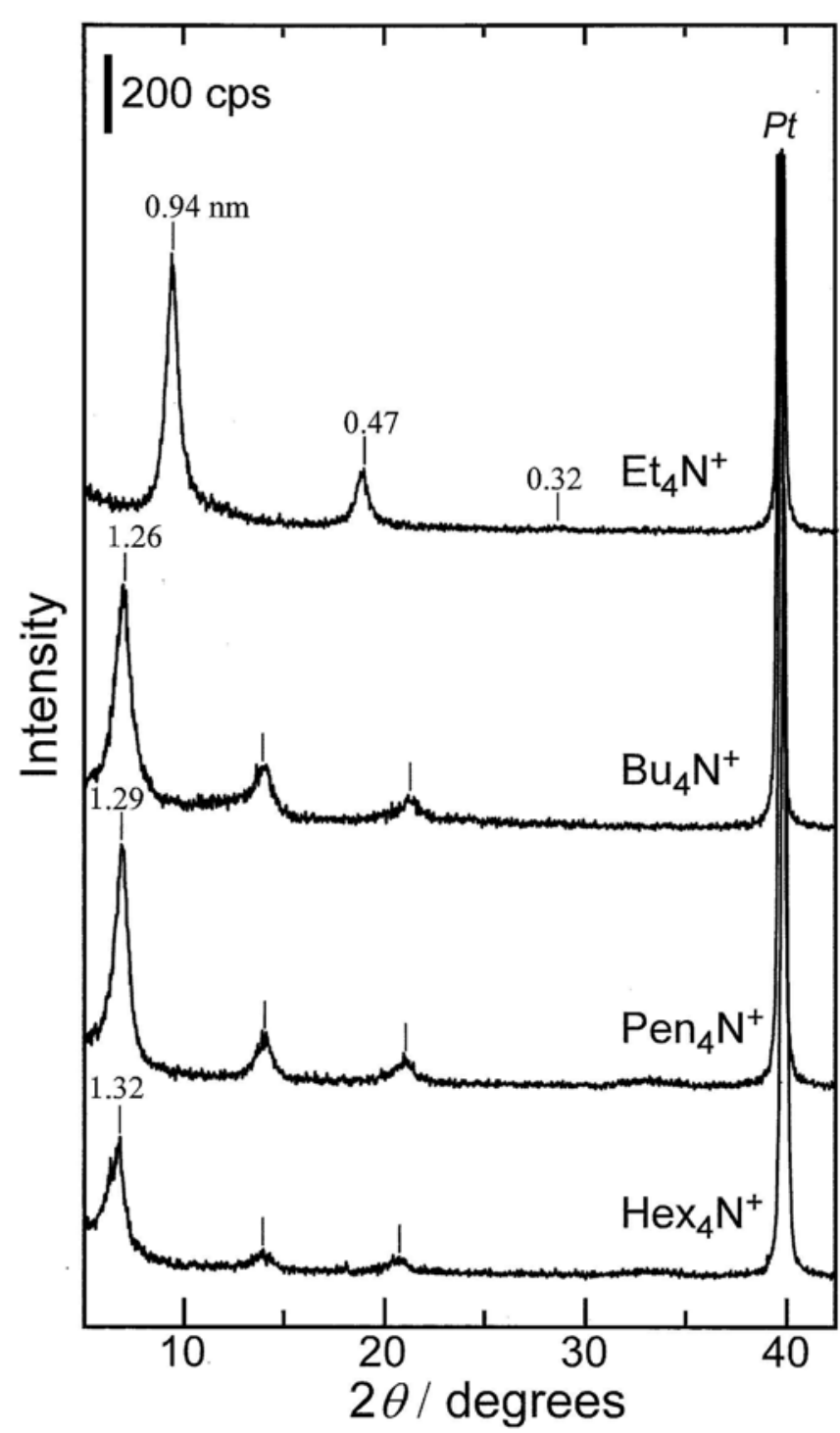

FIG. 1. XRD patterns of the electrodeposited films prepared from $2 \mathrm{mM} \mathrm{MnSO}_{4}$ solutions containing $50 \mathrm{mM}$ chloride salts of various alkylammonium cations by applying a constant potential of $+1.0 \mathrm{~V}$ for $30 \mathrm{~min}$.

TABLE I. Crystallographic radii of tetraalkylammonium ions and the observed $d_{001}$ values.

\begin{tabular}{ccc}
\hline \hline Ion & Radius (nm) & $d_{001}(\mathrm{~nm})$ \\
\hline $\mathrm{Me}_{4} \mathrm{~N}^{+}$ & 0.347 & $0.75,0.98$ \\
$\mathrm{Et}_{4} \mathrm{~N}^{+}$ & 0.400 & 0.94 \\
$\mathrm{Pr}_{4} \mathrm{~N}^{+}$ & 0.452 & 1.03 \\
$\mathrm{Bu}_{4} \mathrm{~N}^{+}$ & 0.500 & 1.26 \\
$\mathrm{Pen}_{4} \mathrm{~N}^{+}$ & 0.529 & 1.29 \\
$\mathrm{Hex}_{4} \mathrm{~N}^{+}$ & 0.560 & 1.32 \\
\hline \hline
\end{tabular}

compounds, that for C4-C6 compounds is quite small. The distance between the $\mathrm{N}^{+}$center and the end of the alkyl chain is calculated by assuming that the alkyl chain is fully expanded in an all-trans conformation. However, this is not true, especially for longer alkyl chain. ${ }^{20}$ Thus,

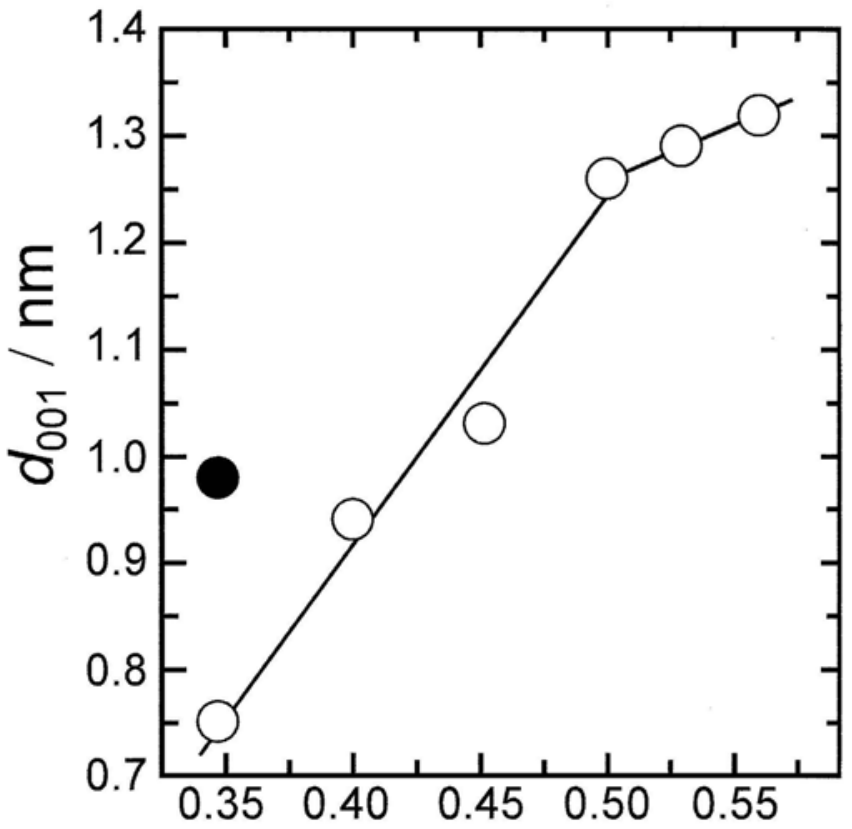

Ionic radius / $\mathrm{nm}$

FIG. 2. Observed $d_{001}$ values were plotted against the radii of tetraalkylammonium ions. The filled circle indicates another $d_{001}$ value observed for the film with $\mathrm{Me}_{4} \mathrm{~N}^{+}$.

we think that the alkyl chains of C5 and C6 ammonium ions are bent to increase the effective charge density in the interlayer, resulting in the smaller increase in the interlayer spacing.

\section{B. Effect of the type of anions}

Figure 3 shows XRD patterns of the films obtained from $2 \mathrm{mM} \mathrm{MnSO}_{4}$ solutions containing $50 \mathrm{mM} \mathrm{Et}_{4} \mathrm{~N}^{+}$ salts with four kinds of counteranions $\left[\mathrm{Cl}^{-}, \mathrm{ClO}_{4}^{-}, p\right.$ toluenesulfonate $\left(\mathrm{PTS}^{-}\right)$, and $\mathrm{BF}_{4}^{-}$]. All the anions provide the same pattern with respect to the peak position and shape, which agrees with the XPS result that no anions are involved in the film prepared at this concentration, as will be described later. On the other hand, the diffraction intensity varied depending on the type of anions. Although the observed order of the peak intensities, $\mathrm{Cl}^{-}>\mathrm{PTS}^{-}>\mathrm{ClO}_{4}^{-}>\mathrm{BF}_{4}^{-}$, is not consistent with the order of ionic seizes, $\mathrm{Cl}^{-}(0.172 \mathrm{~nm}$ in radius $)<\mathrm{BF}_{4}^{-}$ $(0.232 \mathrm{~nm})<\mathrm{ClO}_{4}{ }^{-}(0.240 \mathrm{~nm})<\mathrm{PTS}^{-21,22}$ it is certain that the smallest anion yields the largest pattern. An increase in the diffraction intensity can be ascribed to an increase in the layer ordering. Anions in solution form ion-pairs with alkylammonium cations until just before the formation of Mn oxide, and it is reasonable to assume that self-assembling of the alkylammonium cations to the negatively charged $\mathrm{Mn}$ oxide is interrupted by bulkier anions. PTS ${ }^{-}$, which exhibits the second largest pattern, might facilitate the assembly of the alkyl cations with a specific affinity due to its organic moiety. 


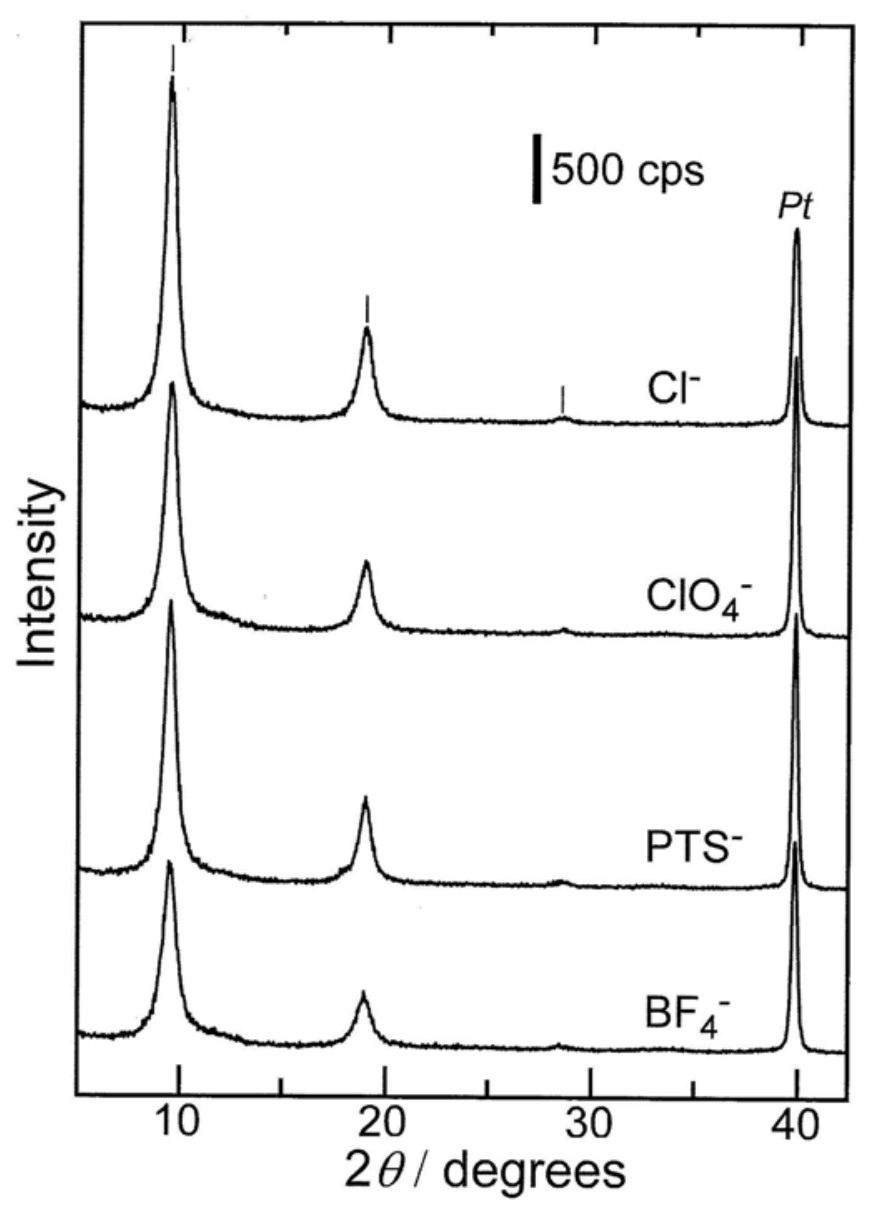

FIG. 3. XRD patterns of the electrodeposited films prepared from $2 \mathrm{mM} \mathrm{MnSO}_{4}$ solutions containing $50 \mathrm{mM} \mathrm{Et}_{4} \mathrm{~N}^{+}$salts of various anions by applying a constant potential of $+1.0 \mathrm{~V}$. The electric charge passed during electrolysis was always $810 \mathrm{mC} \mathrm{cm}^{-2}$.

\section{Effect of bath composition}

Effects of bath composition on the structure of manganese oxide films were investigated with the use of $\mathrm{Et}_{4} \mathrm{~N}^{+}$chloride. Figure 4 illustrates XRD patterns of the films obtained with different $\mathrm{MnSO}_{4}$ concentrations in the range from 2 to $10 \mathrm{mM}$ while maintaining the $\mathrm{Et}_{4} \mathrm{NCl}$

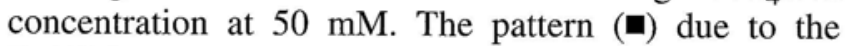
$\mathrm{Et}_{4} \mathrm{~N}^{+}$-intercalated phase shows a maximum intensity at $\left[\mathrm{MnSO}_{4}\right]=2 \mathrm{mM}$, which decreases gradually with an increase in manganese concentration and then disappears completely at $10 \mathrm{mM}$. On the other hand, the product deposited at $\left[\mathrm{MnSO}_{4}\right] \leqslant 1 \mathrm{mM}$ was in powder form and adhered poorly to the substrate. Increasing the $\mathrm{Mn}^{2+}$ concentration causes an increase in the formation rate of manganese oxide, meaning that the reaction conditions become comparable to those of the usual electrodeposition of manganese dioxide, as formulated by

$$
\mathrm{Mn}^{2+}+2 \mathrm{H}_{2} \mathrm{O} \rightarrow \mathrm{MnO}_{2}+4 \mathrm{H}^{+}+2 e^{-} \text {. }
$$

On the other hand, at manganese concentrations of $3-5 \mathrm{mM}$ the pattern $(\bullet)$ with $d_{001}=0.73 \mathrm{~nm}$ appears,

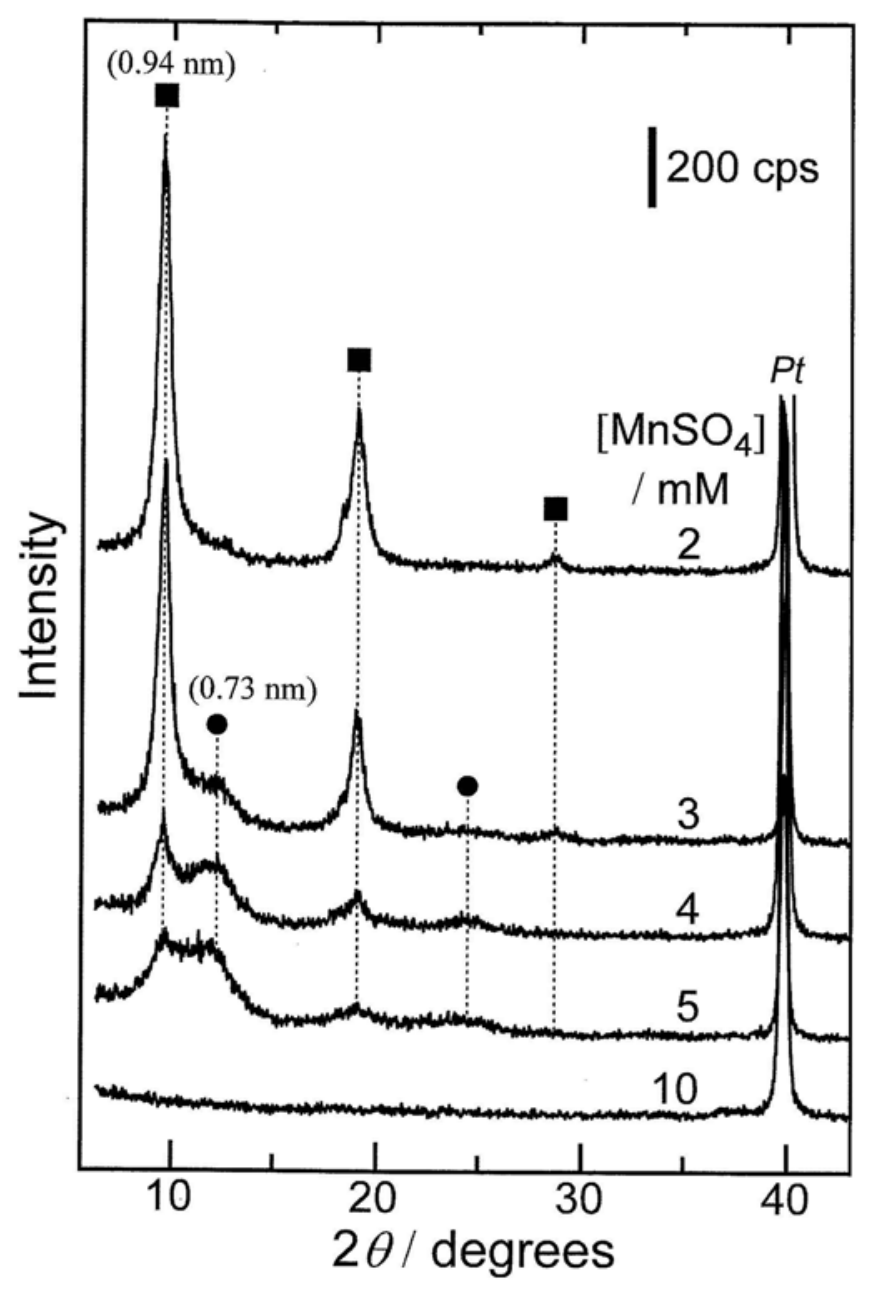

FIG. 4. XRD patterns of the electrodeposited films obtained at $+1.0 \mathrm{~V}$ from $50 \mathrm{mM} \mathrm{Et}_{4} \mathrm{NCl}$ solutions containing $\mathrm{MnSO}_{4}$ at the indicated concentrations. The charge passed during electrodeposition was always $810 \mathrm{mC} \mathrm{cm}^{-2}$.

which is characteristic of a layered product accommodating cations smaller than water molecules. The source of the small cations incorporated will be discussed later.

The patterns obtained from $2 \mathrm{mM} \mathrm{MnSO}_{4}$ solutions with different concentrations of $\mathrm{Et}_{4} \mathrm{NCl}$ are given in Fig. 5. Intensities of the diffraction peaks ( $\square$ ) arising from the $\mathrm{Et}_{4} \mathrm{~N}^{+}$-intercalated phase reach a maximum at $\left[\mathrm{Et}_{4} \mathrm{NCl}\right]=50 \mathrm{mM}$ and decrease at the higher concentrations. At $25 \mathrm{mM}$, another phase $(\bullet)$, which is again characteristic of the product with small cations, appears and becomes predominant at $10 \mathrm{mM}$ or less.

To interpret the above diffraction behavior, XPS measurements were conducted for the films made with $\mathrm{Et}_{4} \mathrm{NCl}$ at concentrations of 5,50 , and $200 \mathrm{mM}$. The resulting spectra for the Mn $2 p, \mathrm{~N} 1 s, \mathrm{Cl} 2 p$, and $\mathrm{O} 1 s$ core electronic transitions are displayed in Fig. 6. Here, all spectra were normalized in intensity with respect to the Mn $2 p$ peaks to allow easier comparisons. The Mn $2 p$ region consists of a spin-orbit doublet attributed to the Mn $2 p_{1 / 2}$ and $\mathrm{Mn} 2 p_{3 / 2}$ states around 654 and $642 \mathrm{eV}$. The precise 


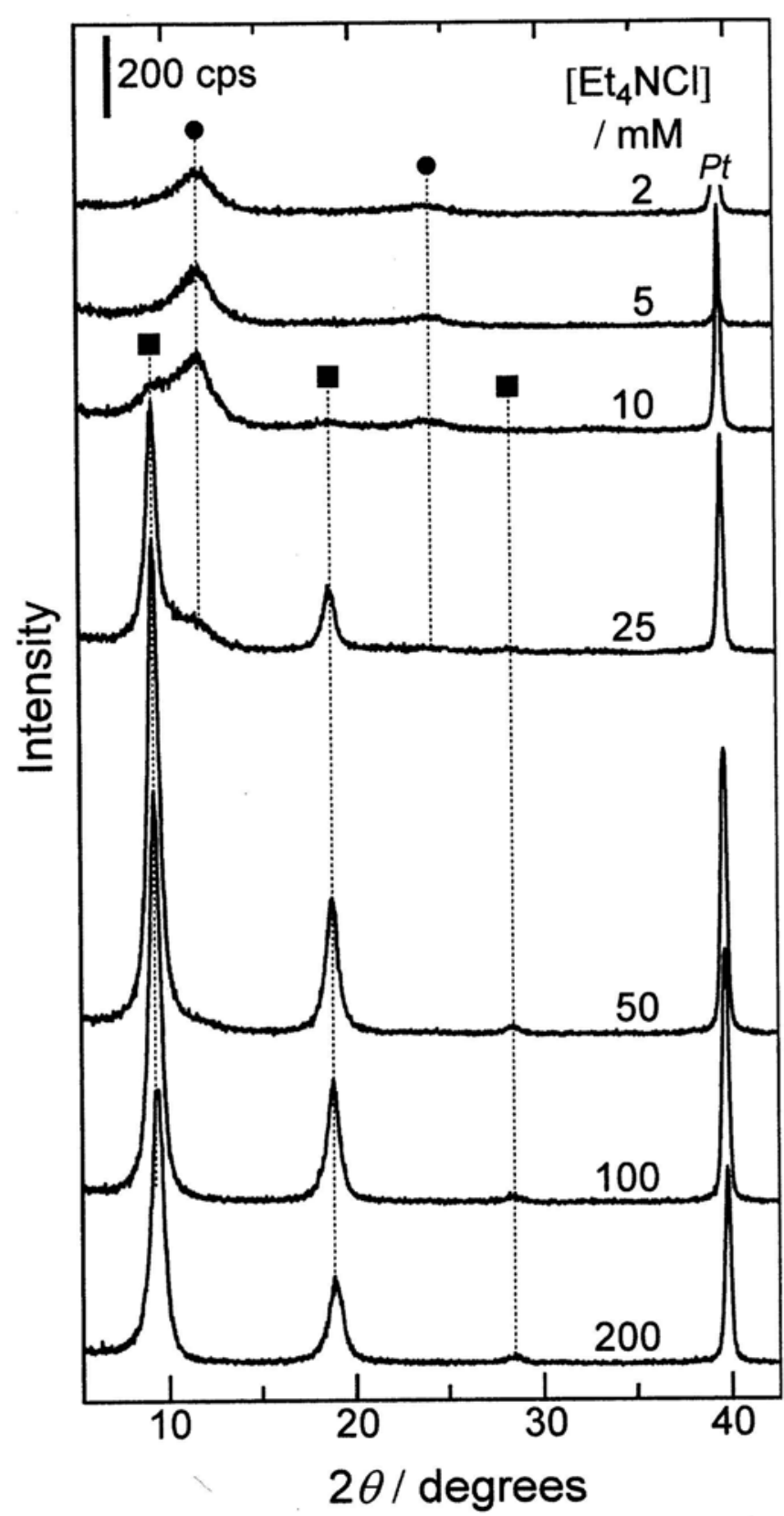

FIG. 5. XRD patterns of the electrodeposited films obtained at $+1.0 \mathrm{~V}$ from $2 \mathrm{mM} \mathrm{MnSO}_{4}$ solutions containing $\mathrm{Et}_{4} \mathrm{NCl}$ at the indicated concentrations. The charge passed during electrodeposition was always $810 \mathrm{mC} \mathrm{cm}^{-2}$.

determination of manganese oxidation states from the Mn $2 p_{3 / 2}$ peak is difficult because the contributions of $\mathrm{Mn}^{4+}(642 \mathrm{eV}), \mathrm{Mn}^{3+}(642-641 \mathrm{eV})$, and $\mathrm{Mn}^{2+}(640 \mathrm{eV})$ are too close to each other. ${ }^{23,24}$ However, all the Mn $2 p_{3 / 2}$ peaks are visible around $642 \mathrm{eV}$, and it is certain that these three films are composed mainly of $\mathrm{Mn}^{4+}$.

In Fig. 6(b), the sample prepared at $5 \mathrm{mM}$, which gave the diffraction pattern with small interlayer, presents a very weak nitrogen signal, indicating a trace amount of alkylammonium ions being incorporated into the film. At
$50 \mathrm{mM}$ where the largest pattern was taken, we can see a peak at $401.4 \mathrm{eV}$ assignable to positively charged nitrogen belonging to $\mathrm{Et}_{4} \mathrm{~N}^{+}$. ${ }^{25}$ For the $\mathrm{Cl} 2 p$ region, no feature is observed, suggesting that all $\mathrm{Et}_{4} \mathrm{~N}^{+}$ions incorporated are associated with the negative charges on manganese oxide layers. Using the peak areas of $\mathrm{N} 1 s$ and Mn $2 p_{3 / 2}$ and their sensitivity factors, the molar ratio of $\mathrm{Et}_{4} \mathrm{~N}^{+}$to manganese was calculated to be 0.21 , which is somewhat smaller than the reported values for bulk $\mathrm{K}$ birnessite $(0.25-0.33) .^{8,26,27}$ At $200 \mathrm{mM}$, the $\mathrm{N} 1 s$ peak is enlarged, accompanying the appearance of a $\mathrm{Cl} 2 p$ signal that consists of doublet peaks at 198.0 and $199.8 \mathrm{eV}$, corresponding to the $2 p_{3 / 2}$ and $2 p_{1 / 2}$ states. In this case, $\mathrm{Et}_{4} \mathrm{~N}^{+}$cations are probably associated not only with the manganese oxide layers but also with $\mathrm{Cl}^{-}$anions, and this may be responsible for the decrease in crystallinity of the product (Fig. 5). The molar ratios of $\mathrm{N}$ and $\mathrm{Cl}$ to $\mathrm{Mn}$ were estimated to be 0.31 and 0.09 , respectively. Assuming that $\mathrm{Cl}^{-}$anions are coupled with $\mathrm{Et}_{4} \mathrm{~N}^{+}$ions, the $\mathrm{Et}_{4} \mathrm{~N}^{+}$ fraction interacting with the manganese oxide layers is $0.22(0.31-0.09)$, in good agreement with the $\mathrm{Et}_{4} \mathrm{~N}^{+} / \mathrm{Mn}$ molar ratio $(0.21)$ obtained at $\left[\mathrm{Et}_{4} \mathrm{NCl}\right]=50 \mathrm{mM}$.

In the $\mathrm{O} 1 s$ region [Fig. 6(d)], three different contributions are observed at 529.6, 530.8-531.0, and 532.8$533.1 \mathrm{eV}$, which can be assigned to oxide (Mn-O-Mn), hydroxide $(\mathrm{Mn}-\mathrm{OH})$, and structural water, respectively. ${ }^{28}$ The area contribution of hydroxide for the film prepared at $5 \mathrm{mM}$ is larger than those of other films, suggesting a larger content of protons. The average oxidation state of manganese was assessed on the basis of the peak area contributions of the $\mathrm{Mn}-\mathrm{O}-\mathrm{Mn}$ and $\mathrm{Mn}-$ $\mathrm{OH}$ components (Table II). The oxidation levels in the fifth column were calculated from the following equation ${ }^{29}$ :

Oxidation state $=$

$$
\frac{\left[\mathrm{IV} \times\left(S_{\mathrm{Mn}-\mathrm{O}-\mathrm{Mn}}-S_{\mathrm{Mn}-\mathrm{OH}}\right)+\left(\mathrm{III} \times S_{\mathrm{Mn}-\mathrm{OH}}\right)\right]}{S_{\mathrm{Mn}-\mathrm{O}-\mathrm{Mn}}},
$$

where $S$ stands for the peak area contribution of each component. This equation is based on the assumption that the charge of the Mn oxide is balanced by $\mathrm{Mn}^{3+/ 4+}$, $\mathrm{O}^{2-}$, and $\mathrm{H}^{+}$. However, our products contain other charged species $\left(\mathrm{Et}_{4} \mathrm{~N}^{+}\right.$and $\left.\mathrm{Cl}^{-}\right)$, and the values obtained from the above equation must be modified by subtracting the other cationic contributions, i.e., $\mathrm{Et}_{4} \mathrm{~N}^{+} / \mathrm{Mn}-\mathrm{Cl}^{-} /$ $\mathrm{Mn}$. As a result, we obtained similar values of 3.6-3.7 for three samples, which are typical of birnessite-type $\mathrm{Mn}$ oxides.

\section{Mechanism for the electroformation of layered manganese oxides}

In the case of low $\mathrm{Mn}^{2+}$ concentration with a relatively large amount of other cations such as tetraalkylammonium, the coexisting cations can be incorporated into the manganese oxide deposited. This can be represented by 

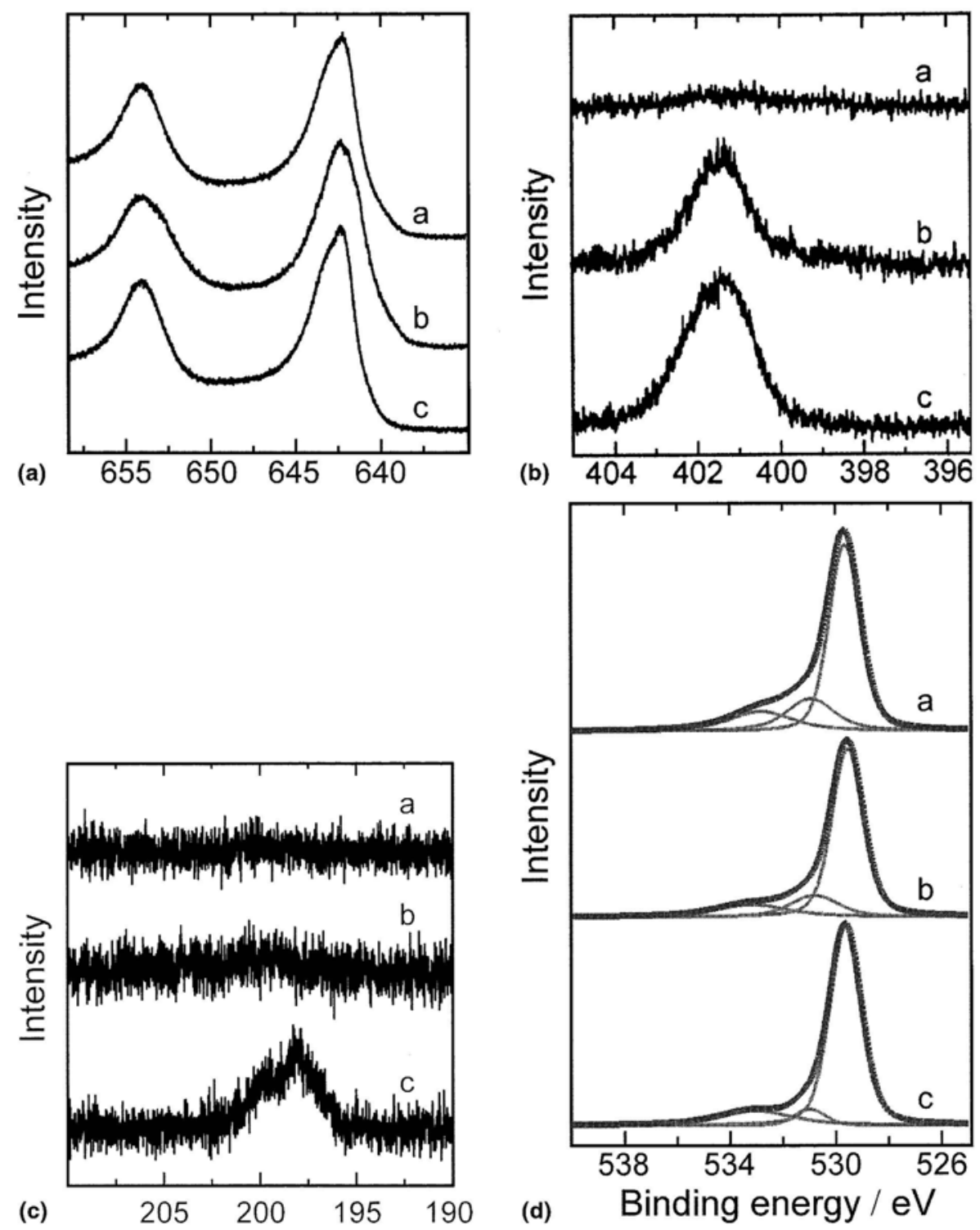

FIG. 6. XPS spectra in (a) $\mathrm{Mn} 2 p$, (b) $\mathrm{N} 1 s$, (c) $\mathrm{Cl} 2 p$, and (d) $\mathrm{O} 1 s$ regions of the electrodeposited films obtained at $+1.0 \mathrm{~V}$ from $2 \mathrm{mM} \mathrm{MnSO}_{4}$ solutions containing $\mathrm{Et}_{4} \mathrm{NCl}$ at (a) $5 \mathrm{mM}$, (b) $50 \mathrm{mM}$, and (c) $200 \mathrm{mM}$. The charge passed during electrodeposition was always $810 \mathrm{mC} \mathrm{cm}^{-2}$

TABLE II. Data obtained from the spectra for the films prepared at different concentrations.

\begin{tabular}{|c|c|c|c|c|c|c|c|}
\hline \multirow[b]{2}{*}[\mathrm{Et}_{4}\mathrm{NCl}]{$(\mathrm{mM})$} & \multicolumn{3}{|c|}{ O $1 s$} & \multirow[b]{2}{*}{ Oxidation state ${ }^{a}$} & \multirow[b]{2}{*}{$\mathrm{N}^{+} / \mathrm{Mn}$} & \multirow[b]{2}{*}{$\mathrm{Cl}^{-} / \mathrm{Mn}$} & \multirow[b]{2}{*}{ Oxidation state ${ }^{b}$} \\
\hline & 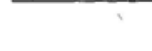 & $\mathrm{BE}(\mathrm{eV})$ & Area \% & & & & \\
\hline \multirow[t]{3}{*}{5} & $\mathrm{Mn}-\mathrm{O}-\mathrm{Mn}$ & 529.6 & 65.1 & 3.7 & 0.07 & 0.00 & 3.6 \\
\hline & $\mathrm{Mn}-\mathrm{OH}$ & 530.9 & 19.2 & & & & \\
\hline & $\mathrm{H}-\mathrm{O}-\mathrm{H}$ & 532.8 & 15.8 & & & & \\
\hline \multirow[t]{3}{*}{50} & $\mathrm{Mn}-\mathrm{O}-\mathrm{Mn}$ & 529.6 & 72.6 & 3.8 & 0.21 & 0.00 & 3.6 \\
\hline & $\mathrm{Mn}-\mathrm{OH}$ & 530.8 & 14.4 & & & & \\
\hline & $\mathrm{H}-\mathrm{O}-\mathrm{H}$ & 533.2 & 13.0 & & & & \\
\hline \multirow[t]{3}{*}{200} & $\mathrm{Mn}-\mathrm{O}-\mathrm{Mn}$ & 529.6 & 80.0 & 3.9 & 0.31 & 0.09 & 3.7 \\
\hline & $\mathrm{Mn}-\mathrm{OH}$ & 531.0 & 5.7 & & & & \\
\hline & $\mathrm{H}-\mathrm{O}-\mathrm{H}$ & 533.1 & 14.2 & & & & \\
\hline
\end{tabular}

${ }^{a}$ Calculated from Eq. (2).

${ }^{\mathrm{b}}$ Modified values obtained by considering the contribution of alkylammonium ion. 


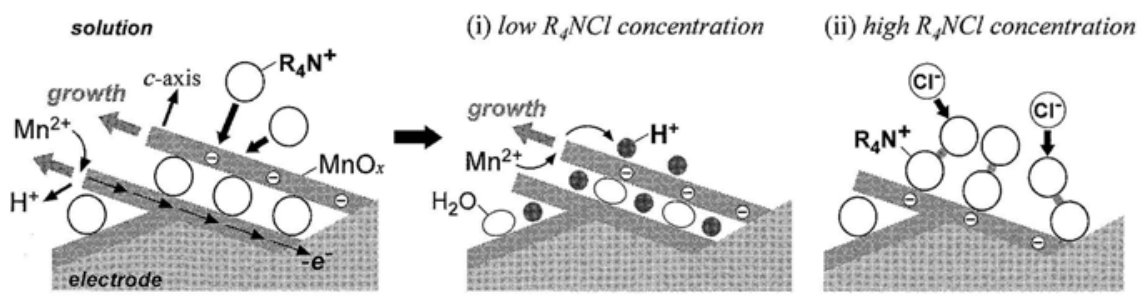

FIG. 7. Schematic illustration of the electrochemical multilayer formation of manganese oxide.

Eq. (3), referring to the usual electrodeposition of $\mathrm{MnO}_{2}$ [Eq. (1)]:

$$
\begin{aligned}
\mathrm{Mn}^{2+}+2 \mathrm{H}_{2} \mathrm{O}+x \mathrm{~A}^{+} \rightarrow & \mathrm{A}_{x} \mathrm{Mn}_{x}^{3+} \mathrm{Mn}_{1-x}^{4+} \mathrm{O}_{2} \\
& +4 \mathrm{H}^{+}+(2-x) e^{-} .
\end{aligned}
$$

A schematic representation for the electrochemical formation of layered manganese oxides with alkylammonium cations is given in Fig. 7. At the beginning, manganese oxide nuclei deposit anodically on polycrystalline platinum surface, and their negative charges are neutralized by the assembly of alkylammonium cations in solution. This restricts the growth direction of manganese oxide to the $a b$ plane, resulting in the lamination of manganese oxide sheets along the $c$ axis. As seen from Eq. (1) or (3), the manganese oxide formation must accompany the generation of protons. In the starting solution with low alkylammonium concentration, these protons can neutralize the negative charges on manganese oxide, yielding a product with small interlayer. At the higher concentration, hydrophobic interaction between alkylammonium molecules becomes important and chloride anions combine with them; i.e., $\mathrm{Cl}^{-}$anions can play the role of terminator.

\section{E. lon-exchange behavior}

Figure 8 displays the XRD patterns of an $\mathrm{Et}_{4} \mathrm{~N}^{+} / \mathrm{MnO}_{x}$ film taken before and after immersion in solutions containing ammonium and alkylammonium ions of varying alkyl chain lengths. The pattern (curve d) after immersion in $\mathrm{Et}_{4} \mathrm{NCl}$ solution is practically the same as that (curve a) of the as-deposited film, confirming that in $\mathrm{Et}_{4} \mathrm{NCl}$ solution the intercalated $\mathrm{Et}_{4} \mathrm{~N}^{+}$cations are stable enough to remain in the interlayer. After immersion in $\mathrm{NH}_{4} \mathrm{Cl}$ solution (curve b), the peaks due to the $\mathrm{Et}_{4} \mathrm{~N}^{+}$intercalated phase disappear and are replaced by two peaks at 0.73 and $0.37 \mathrm{~nm}$. This new pattern demonstrates deintercalation of bulky $\mathrm{Et}_{4} \mathrm{~N}^{+}$ions with accompanying shrinkage of the interlayer. Instead, the interlayer space is occupied by hydrated $\mathrm{NH}_{4}{ }^{+}$ions, where the interlayer distance is determined by the fact that water molecules are larger in size than $\mathrm{NH}_{4}{ }^{+}$. One should note that the film replaced with $\mathrm{NH}_{4}{ }^{+}$presents considerably broader and smaller peaks than the original structure. This feature can be ascribed to a lower degree of the interlayer ordering, rather than to a decrease in the crystal size because the original structure was recovered after re-immersion into $\mathrm{Et}_{4} \mathrm{NCl}$ solution (curve $\mathrm{b}^{\prime}$ ). Balancing the same negative charges with smaller size molecules inevitably produced void volumes, which can be filled

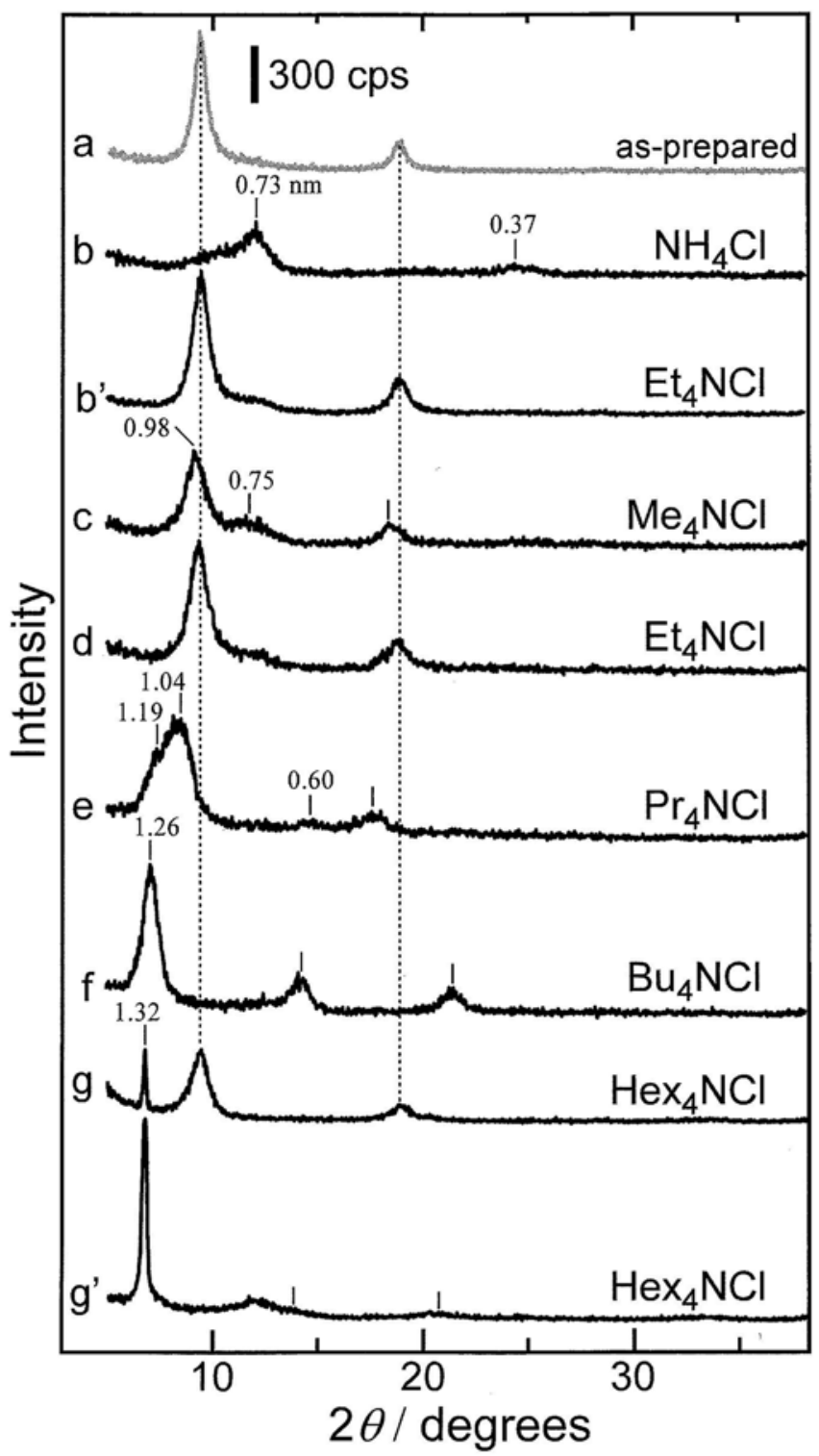

FIG. 8. XRD patterns of an $\mathrm{Et}_{4} \mathrm{~N}^{+} / \mathrm{MnO}_{x}$ film taken (a) before and after being immersed for $(\mathrm{b}-\mathrm{g}) 2$ or $\left(\mathrm{g}^{\prime}\right) 24 \mathrm{~h}$ in $0.1 \mathrm{M}$ solutions of the indicated salts. Curve $\mathrm{b}^{\prime}$ was obtained after immersing film $\mathrm{b}$ into $\mathrm{a}$ $0.1 \mathrm{M} \mathrm{Et}_{4} \mathrm{NCl}$ solution for $2 \mathrm{~h}$. The film deposition was made the same way as that in Fig. 1. 
with water molecules. The sparsely packed interlayer thus made is likely responsible for the poorer interlayer ordering. An opposite tendency is visible for the films immersed in solutions with bulkier cations such as $\mathrm{Bu}_{4} \mathrm{~N}^{+}$(curve f) and $\mathrm{Hex}_{4} \mathrm{~N}^{+}$(curve g). In particular, the 001 peak of the $\mathrm{Hex}_{4} \mathrm{~N}^{+}$-intercalated film becomes narrower and more intense compared to that of the asdeposited film with $\mathrm{Et}_{4} \mathrm{~N}^{+}$, while the peak position is the same as that of the electrodeposited $\mathrm{Hex}_{4} \mathrm{~N}^{+}$film. As seen in curves $\mathrm{g}$ and $\mathrm{g}^{\prime}, \mathrm{Hex}_{4} \mathrm{~N}^{+}$has a slower rate of ion-exchange, and a broadened feature around $12^{\circ}$ is attributable to the water-incorporated phase.

As shown in curve $c$, the immersion into $\mathrm{Me}_{4} \mathrm{NCl}$ solution provides two phases with $d_{001}=0.98$ and $0.75 \mathrm{~nm}$. This combination of the peak positions could also be seen for the as-deposited $\mathrm{Me}_{4} \mathrm{~N}^{+} / \mathrm{MnO}_{x}$ film, as described before. ${ }^{15}$ In curve e, the pattern with $d_{001}=$ $1.04 \mathrm{~nm}$ obtained from a $\mathrm{Pr}_{4} \mathrm{~N}^{+}$-containing solution corresponds to the accommodation of one molecular layer of unhydrated $\mathrm{Pr}_{4} \mathrm{~N}^{+}$ions with the $C_{2}$ rotation axis normal to the plane of manganese oxide. On the other hand, the contribution with larger $d$-spacings $\left(d_{001}=1.19 \mathrm{~nm}\right.$ and $d_{002}=0.60 \mathrm{~nm}$ ) may reflect a structure with the $C_{3}$ rotation axis being normal to the manganese oxide layer. The interlayer distance ratio of the latter to the former is theoretically calculated to be 1.15 , which is close to the observed value 1.14 (1.19/1.04).

\section{CONCLUSIONS}

Multilayered manganese oxide films having various interlayer distances can be formed anodically on a Pt electrode from aqueous $\mathrm{Mn}^{2+}$ solutions with different $n$-tetra-alkylammonium compounds. The interlayer distance increased almost linearly with an increase in alkyl chain length up to $\mathrm{C} 4$, and the change became obviously small among C4-C6 compounds. The multilayer formation with $\mathrm{Et}_{4} \mathrm{~N}^{+}$ions can be achieved at a $\mathrm{MnSO}_{4}$ concentration of less than $10 \mathrm{mM}$. The best product in terms of crystallinity was obtained from a bath that consists of $2 \mathrm{mM} \mathrm{MnSO}_{4}$ and $50 \mathrm{mM} \mathrm{Et}_{4} \mathrm{NCl}$, where $\mathrm{Cl}^{-}$anions were not detected. At low alkylammonium concentrations $(<10 \mathrm{mM})$, a product intercalated with hydrated protons was formed. At the higher concentration, $\mathrm{Et}_{4} \mathrm{~N}^{+}$ cations can be associated not only with the negatively charged manganese oxide but also with $\mathrm{Cl}^{-}$, and this may cause a decrease in crystallinity of the products. $\mathrm{Et}_{4} \mathrm{~N}^{+}$ cations being intercalated in the electrodeposited film are replaceable with various cations in solution by ionexchange while the framework structure is retained.

\section{ACKNOWLEDGMENT}

This research was supported in part by the Japan Society of the Promotion of Science (16750175).

\section{REFERENCES}

1. C.J. Motocha, E.J. Elzinga, and D.L. Sparks: Reactivity of $\mathrm{Pb}(\mathrm{II})$ at the $\mathrm{Mn}(\mathrm{III}, \mathrm{IV})$ (oxyhydr)oxide-water interface. Environ. Sci. Technol. 35, 2967 (2001).

2. H. Cao and S.L. Suib: Highly efficient heterogeneous photooxidation of 2-propanol to acetone with amorphous manganese oxide catalysts. J. Am. Chem. Soc. 116, 5334 (1994).

3. B. Ammundsen and J. Paulsen: Novel lithium-ion cathode materials based on layered manganese oxides. Adv. Mater. 13, 943 (2001).

4. B. Lanson, V.A. Drits, E. Silvester, and A. Manceau: Structure of $\mathrm{H}$-exchanged hexagonal birnessite and its mechanism of formation from Na-rich monoclinic buserite at low pH. Am. Mineral. 85, 826 (2000).

5. J. Luo and S.L. Suib: Formation and transformation of mesoporous and layered manganese oxides in the presence of longchain ammonium hydroxides. Chem. Commun. 1031 (1997).

6. S.L. Brock, M. Sanabria, S.L. Suib, V. Urban, P. Thiyagarajan, and D.I. Potter: Particle size control and self-assembly process in novel colloids of nanocrystalline manganese oxide. J. Phys. Chem. B 103, 7416 (1999).

7. D.C. Golden, C.C. Chen, and J.B. Dixon: Transformation of birnessite to buserite, todorokite, and manganite under mild hydrothermal treatment. Clays Clay Miner. 35, 271 (1987).

8. S. Ching, D.J. Petrovay, M.L. Jorgensen, and S.L. Suib: Synthesis of layered birnessite-type manganese oxides. Inorg. Chem. 36, 883 (1997).

9. Y.F. Shen, S.L. Suib, and C.L. O'Young: Effects of inorganic cation templates on octahedral molecular sieves of manganese oxide. J. Am. Chem. Soc. 116, 11020 (1994).

10. J. Luo, A. Huang, S.H. Park, S.L. Suib, and C. O'Young: Crystallization of sodium-birnessite and accompanied phase transformation. Chem. Mater. 10, 1561 (1998).

11. G.H.A. Therese and P.V. Kamath: Electrochemical synthesis of metal oxides and hydroxides. Chem. Mater. 12, 1195 (2000).

12. M. Nakayama, A. Tanaka, Y. Sato, T. Tonosaki, and K. Ogura: Electrodeposition of manganese and molybdenum mixed oxide thin films and their charge storage properties. Langmuir 21, 5907 (2005).

13. M. Nakayama, S. Konishi, A. Tanaka, and K. Ogura: A novel electrochemical method for preparation of thin films of layered manganese oxides. Chem. Lett. (Jpn.) 33, 670 (2004).

14. M. Nakayama, H. Tagashira, S. Konishi, and K. Ogura: A direct electrochemical route to construct a polymer/manganese oxide layered structure. Inorg. Chem. 43, 8215 (2004).

15. M. Nakayama, S. Konishi, H. Tagashira, and K. Ogura: Electrochemical synthesis of layered manganese oxides intercalated with tetra-alkylammonium ions. Langmuir 21, 354 (2005).

16. M. Nakayama, H. Komatsu, S. Ozuka, and K. Ogura: Immobilization of methylene blue between electrodeposited manganese oxide multilayers. Chem. Lett. (Jpn.) 34, 1420 (2005).

17. M. Nakayama and H. Tagashira: Electrodeposition of layered manganese oxide nanocomposites intercalated with strong and weak polyelectrolytes. Langmuir 22, 3864 (2006).

18. C.M. Criss and M.J. Mastroianni: Some observations on the viscosity coefficients of ions in various solvents. J. Phys. Chem. 75, 2532 (1971).

19. N. Saha and B. Das: Viscosities of some symmetrical tetraalkylammonium salts in acetonitrile (at 288.15, 298.15, 308.15, and 318.15) K. J. Chem. Eng. Data 45, 1125 (2000).

20. J. Fink, C.J. Kiely, D. Bethell, and D.J. Schiffrin: Selforganization of nanosized gold particles. Chem. Mater. 10, 922 (1998). 
21. H.K. Roobottom, D.B. Jenkins, J. Passmore, and L. Glasser: Thermochemical radii of complex ions. J. Chem. Educ. 76, 1570 (1999).

22. A.A. Rudolf Holze: Ion size and size memory effects with electropolymerized polyaniline. Synth. Met. 131, 61 (2002).

23. T. Hasemi and A.W. Brinkman: X-ray photoelectron spectroscopy of nickel manganese oxide thermisters. J. Mater. Res. 7, 1278 (1992).

24. B.J. Aronson, C.F. Blanford, and A. Stein: Synthesis, characterization, and ion-exchange properties of zinc and magnesium manganese oxides confined within MCM-41 channels. J. Phys. Chem. B 104, 449 (2000).

25. A.S. Zahr, M. Villiers, and M.V. Pishko: Encapsulation of drug nanoparticles in self-assembled macromolecular nanoshells. Langmuir 21, 403 (2005).

26. H. Kanoh, W. Tang, Y. Makita, and K. Ooi: Electrochemical intercalation of alkali-metal ions into birnessite-type manganese oxide in aqueous solution. Langmuir 13, 6845 (1997).

27. R. Chen, P. Zavalij, and M.S. Whittingham: Hydrothermal synthesis and characterization of $\mathrm{K}_{x} \mathrm{MnO}_{2} \cdot y \mathrm{H}_{2} \mathrm{O}$. Chem. Mater. 8, 1275 (1996).

28. M. Chigane and M. Ishikawa: Manganese oxide thin film preparation by potentiostatic electrolysis and electrochromism. J. Electrochem. Soc. 147, 2246 (2000).

29. M. Toupin, T. Brouse, and D. Blanger: Charge storage mechanism of $\mathrm{MnO}_{2}$ electrode used in aqueous electrochemical capacitor. Chem. Mater. 16, 3184 (2004). 